ESEM-EDS Investigation of the Weathering of a Heritage

\section{Sydney Sandstone}

Kin Hong Ip, Barbara Stuart, ${ }^{*}$ Abhi Ray, and Paul Thomas

Department of Chemistry and Forensic Sciences, University of Technology Sydney, P.O. Box 123,
Broadway NSW 2007, Australia

Abstract: The degradation of Sydney sandstone used to build the heritage St Mary's Cathedral in Sydney, Australia, has been investigated using environmental scanning electron microscopy combined with energy dispersive X-ray spectroscopy. This technique provided the structural details of the cementing clay and an elemental characterization the sandstone. The observed differences in the elemental composition of the ing. The results support the substitution theory that $\mathrm{Fe}^{3+}$ replaces $\mathrm{Al}^{3+}$ in the keolinite clay component upon weathering. An examination of the impurities present prior to a nonstructural iron removal treatment revealed the presence of minerals that may provide a source of the elements responsible for the substitution process.

Key words: sandstone, clay, kaolinite, weathering, environmental scanning electron microscopy, energy dispersive X-ray spectroscopy

\section{INTRODUCTION}

Various 19th century heritage buildings located in Sydney Australia, are built from locally quarried "yellow block" sandstone. Sydney yellow block sandstones typically contain $60-68 \%$ sand bound together with a clay-based matrix $(16-25 \%)$ and small quantities of iron-rich impurities (McNally \& Franklin, 2000). Oxidation of the iron-rich minerals in the stone produces an attractive golden color. As a resul of exposure to environmental factors, a number of Sydney heritage buildings are showing evidence of deterioratio Although the sandstone does retain detailed carving and the integrity of the stone structure, the material becomes relatively brittle and susceptible to damage.

St Mary's Cathedral is a significant public building in central Sydney and was built in the mid-19th century of sandstone quarried in the Pyrmont area of the city (Fig. 1). Decayed sandstone from the Cathedral has been replaced by new Pyrmont sandstone as part of a restoration program by the Government Architect's Office of the New South Wales Department of Commerce in collaboration with Gosfor Quarries Pty Ltd. To best manage the conservation of heritage sandstone buildings, including St Mary's Cathedra there is a need to fully understand the nature of the degradation process observed.

In this study, the clay component of sandstone re moved from St Mary's Cathedral has been examined using environmental scanning electron microscopy (ESEM) combined with elemental analysis via energy dispersive X-ray spectroscopy (EDS). This study forms part of a series investigations dealling with the different aspects of the weathering process of Sydney sandstones (Friolo et al., 2003, 2004, 2005a, 2005b; Ip et al., 2008a, 2008b). The earlie Received March 15, 2010; accepted October 8, 2010
*Corvesponding studies have involved the use of spectroscopic techniques and X-ray diffraction to examine the structural changes to weathered clay, and thermal analysis has revealed changes to the transitions associated with the clay. Such studies have been used to postulate a substitution model responsible for the observed physical changes observed upon weatherin However, as this model involves changes to the elementa composition of the clay, it was believed important to chatacterize the changes to the elements present in the clay structure and EDS provides a suitable tool.

\section{Materials and Methods} Sandstone samples from St Mary's Cathedral were supplied
by Gosford Quarries Pty Ltd, Australia. The samples obtained were the more decayed yellow block sandstones th had been removed and replaced. The weathered surfaces were separated from the unweathered cores of thed surfaces stones by use of a diamond saw, and small amounts of a diamond saw, and small amounts of of freshly exposed unweathered Sydney sandstone and weathered stone are illustrated in Figure 2 .

The clay-based material was separated from the sandstone samples for SEM analysis. Both weathered and unweathered sandstones were manually crushed using a mor and pestle and then mixed with distilled water $\left(5 \mathrm{gL}^{-1}\right)$. An ultrasonic probe with frequency of $20 \mathrm{kHz}$ and energy of $20 \mathrm{~W}$ was used to dislodge the clay-based material from the sand particles (Schmidt et al., 1999; Roscoe et al., 2000). The decanted clay materials were suspended in distilled water and particles $\leq 2 \mu \mathrm{m}$ were collected using a gravity settling method according to Stokes' Law (Rutledge et al., 1967; Carroll, 1970). The clay collected by centrifugation was dried in a $50^{\circ} \mathrm{C}$ oven overnight and separated into two portions. One portion was stored in a desiccator until



Figure 1. St Mary's Cathedral, Sydney



Figure 2. Unweathered (left) and weathered (right) Sydney sandstone.

analysis, and the second portion was further treated with $\mathrm{Na}_{2} \mathrm{~S}_{2} \mathrm{O}_{3} \cdot 5 \mathrm{H}_{2} \mathrm{O}$ and $\mathrm{NaHCO}_{3}$ to remove nonstructural iron from the clay samples (Mehra \& Jackson, 1960).

A Philips XL30 ESEM, on which an energy dispersive X-ray spectrometer was mounted, was used for the analysis of the clay samples before and after the removal of nonstruc-

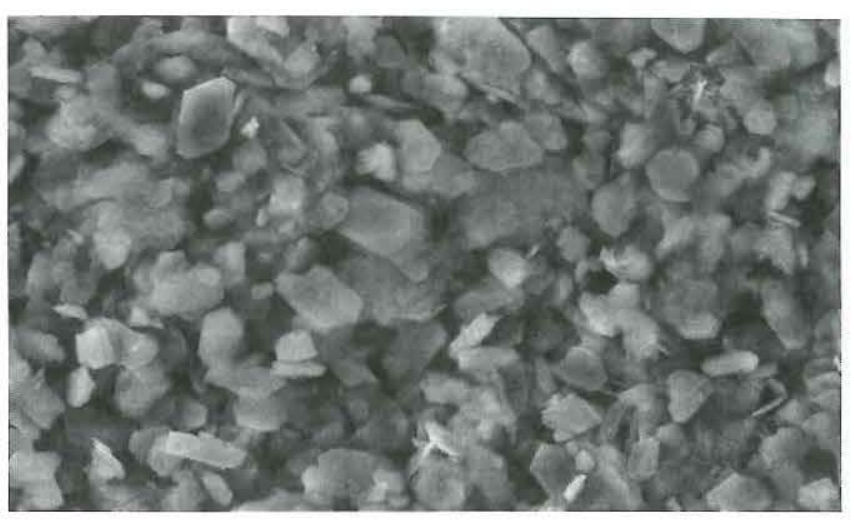

Figure 3. Electron micrograph of unweather
tural iron removal (156 $\mu \mathrm{m}$ width of field).

tural iron from each sample. Separated clay samples were secured onto the sample holder using double-sided tape. An accelerating voltage of $15.0 \mathrm{kV}$ was used in the microscopic analysis, and a backscattering detector was used to collect electronic images. Images were produced along the sides and the centers of each sample, and different magnifications from the same point of the samples were also recorded.

\section{REsULTS}

The electron micrographs of both the weathered and unweathered cementing clays after nonstructural iron removal show that a large number of hexagonal platelets of various sizes are present. There is no dramatic difference in the appearance of the weathered and unweathered clay platelets. However, for the unweathered samples, there appears to be more regular sized hexagonal platelets (Fig. 3), while the weathered samples generally show smaller and more irregular sized and shaped platelets with some areas of fused particles (Fig. 4). The EDS results for both the unweathered and weathered clays after nonstructural iron removal are shown in Figures 5 and 6, respectively. The unweathered clay contains significant amounts of $\mathrm{Si}, \mathrm{Al}, \mathrm{O}$, and some $\mathrm{K}$ (Fig. 5). Weathered specimens also show the presence of $\mathrm{Si}$, $\mathrm{Al}, \mathrm{O}$, and $\mathrm{K}$, but also contain $\mathrm{Ti}$ and $\mathrm{Cl}$ (Fig. 6).

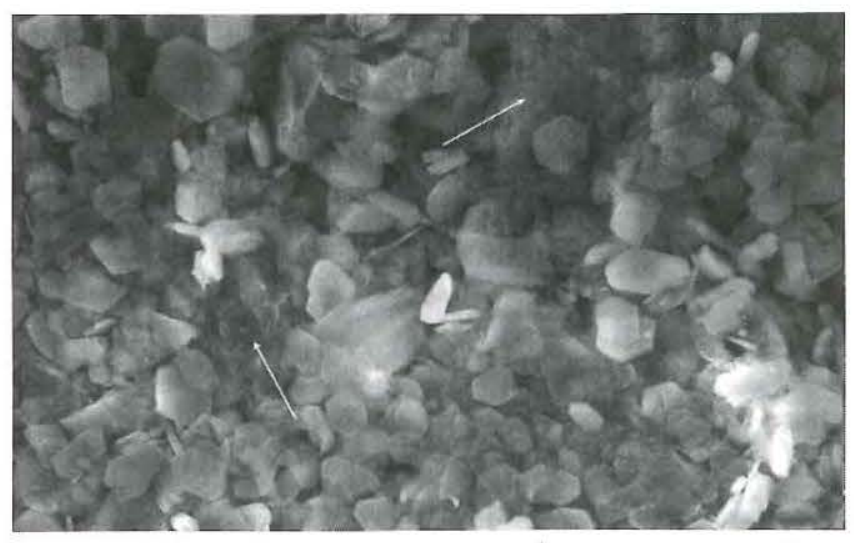

weathered clay after nonstructural iron removal (156 $\mu \mathrm{m}$ width of field). 




Figure 5. EDS spectrum of unweathered clay after nonstructural

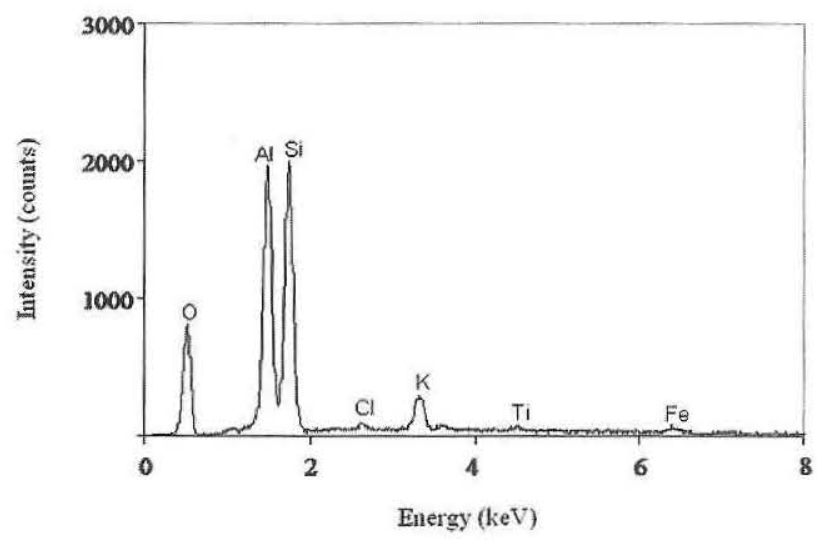

Figure 6. EDS spectrum of weathered clay after nonstructural iron removal.

To investigate the potential source of elements in the weathered specimens post-nonstructural iron treatment, ESEM was used to identify the possible presence of impurities in the clays prior to treatment. It was found that there were small amounts of other minerals observed among the clay platelets, and these exhibited brighter images by comparison with the clay particles due to their higher atomic numbers. Higher magnification images of these minerals were recorded, and the EDS results were obtained for a range of impurities. Although several types of mineral impurities were observed in the unweathered clay, their presence was minimal and they were generally small in size. The weathered clays appeared to contain a larger amount of impurities, and the particle size was increased. Based on the EDS analyses, two common types of impurities were observed in the unweathered clay. Both types contained $\mathrm{O}, \mathrm{Al}$, $\mathrm{Si}, \mathrm{K}$, and $\mathrm{Fe}$, but one type also contained $\mathrm{Na}$ and $\mathrm{Mg}$ while the other also contained $\mathrm{S}$. For the impurities found in the weathered clay, $\mathrm{O}, \mathrm{Al}, \mathrm{Si}, \mathrm{K}$, and $\mathrm{Fe}$ were detected, and $\mathrm{Ti}$ was found in addition in certain impurities.

Discussion

ESEM-EDS provides detailed information about the weathering of the cementing clay in a Sydney sandstone. The clay samples were shown to contain loose or stacked hexagonal platelets with sizes in the $2-5 \mu \mathrm{m}$ range. These are typically the shapes and sizes of kaolinite clay platelets, where the preferred orientation of the basal plane $\left(\begin{array}{lll}0 & 0 & 1\end{array}\right)$ results in a stacking that forms book-like clay particles (Murray, 1995). Smaller clay platelets and platelets with irregular shapes appear to have been formed in the weathered samples and potentially indicate the destabilization of the aluminosilicate crystal structure. The EDS results show that the elements $\mathrm{Fe}, \mathrm{Ti}$, and $\mathrm{Cl}$ are included in the weathered clay.

The appearance of Fe in the aluminosilicate clay structure of clay is believed to be the result of isomorphous substitution (Malden \& Meads, 1967; Farmer et al., 1971; McBride et al., 1975; Rozenson \& Heller-Kallai, 1977; Komusinski et al., 1981). Iron in its ferric form $\left(\mathrm{Fe}^{3+}\right)$ can replace $\mathrm{Al}^{3+}$ in the octahedral sites of the aluminosilicate structure. Although the two ions have equivalent charges, the ionic radius of $\mathrm{Fe}^{3+}(128 \mathrm{pm})$ is more than double of the ionic radius of $\mathrm{Al}^{\mathrm{P}+}(50 \mathrm{pm})$. The stress introduced in the crystal lattice through substitution greatly decreases the crystallinity of the kaolinite structure in the cementing materials and may rupture the platelets. In addition, $\mathrm{Fe}^{3+} / \mathrm{Al}^{3+}$, together with $\mathrm{K}^{+}$, can also substitute $\mathrm{Si}^{4{ }^{4}}$ in the tetrahedral sites. Although the charge balance is accommodated in this form of substitution, this phenomenon is less common due to the extra strain introduced into the crystal lattice (Meads \& Malden, 1975; Hall, 1980; Petit \& Decarreau, 1990). However, an increase in $\mathrm{K}$ concentration in the weathered clay suggests that this type of substitution has occurred upon weathering. Substitutions of any kind are likely to destabilize or destroy the crystal structure of the clay, resulting in the breakdown of its aluminosilicate layers upon weathering. The ESEM-EDS results support the findings obtained from thermal analysis, $\mathrm{X}$-ray diffraction, and spectroscopy, which also provided evidence of an isomorphous stbstitution of $\mathrm{Al}^{3+}$ by $\mathrm{Fe}^{3+}$ (Friolo et al., 2003, 2005a; Ip et al., 2008a, 2008b). It has been reported in some studies that the increase in total iron content in clay samples, particularly that of kaolinite, is associated with an exponential decrease in crystallinity of the kaolinite crystal structure with increasing time (Hinckley, 1963; Mestdagh et al., 1980; Hassan \& Salem, 2002). This may indicate that a small amount of iron substituted into the crystal structure of the cementing clay could esult in a significant effect on the properties of the clay. An EDS examination of the impurities present in the clays prior to the iron removal treatment revealed that other minerals were present. Such minerals provide a potential source of the elements appearing in the weathered clay structures. The intensities of Al, $\mathrm{Si}$, and $\mathrm{O}$ in the EDS results suggest the presence of aluminosilicate minerals. In addiof several minerals or salts. The ESEM-EDS result of of several minerals or salts. The ESEM-EDS results of anclay give a god indication that the observed cementing clay give a good indication that the observed mineral is pyrite $\left(\mathrm{Fe}_{2}\right)$ or jarosite $\left(\mathrm{FeSO}_{4} \cdot 2 \mathrm{H}_{2} \mathrm{O}\right.$ ) due to the presence lation of Fe rich impurities and Ti compounds observed in the weathered samples. Many of the impurities in the cementing clay samples are believed to originate from the sandstone or are the products of the weathering process. Iron and titanium impurities are often found in clay as hematite, siderite, pyrite, anatase, and rutile (Weaver, 1968 Maynard et al., 1969; Asmatulu, 2002). Other sources of iron may include building materials containing iron, stee loofing, water piping, and window or door frames. Given the proximity of the cathedral to the ocean, the $\mathrm{Cl}$ observed may be derive from the increased salt in the environment.

\section{CONCLUSIONS}

ESEM-EDS provides structural details of the cementing clay in a Sydney heritage sandstone. Hexagonal clay platelets were observed and mineral impurities were present, partic ularly in the weathered clay samples. The elemental composition santion win the alumin pution within the ald $\mathrm{A}^{3+}$, was indicas by ESEM-EDS. Ore places $\mathrm{A}^{3+}, \mathrm{ma}^{3+} \mathrm{Cr}^{3+}$ tuting for $\mathrm{Si}^{4+}$ in the tetrated

\section{ACKNOWLEDGMENTS}

The authors wish to acknowledge the support of the GovArchitect's Office of the New South Wales De ment of Commerce and Gosford Quarries Pty Ltd.

\section{REFERENCES}

ASMATULU, R. (2002). Removal of the discolouring contaminan

of an East Georgia kaolin clay and its dewatering. Turkish J Eng
Environ Sci 26, 447-453. during two different pollution regimes. In Processes of Urba Stone Decay: Proceedings of SWAPNET "95, Stone Weathering Warke, P.A. (Eds.), pp. 47-52. London: Donhend

CARROLL, D. (1970). Clay Minerals: A Guide to Their X-Ray Identification. Boulder, $\mathrm{CO}$ : Geological Society of Americ.

rmer, V.C., Russell, J.D., McHardy, W.J., Newman, A.C.D. AhLRICHS, J.L. \& RimSATTE, J.Y.H. (1971). Evidence for loss of protons and octahedral iron from oxidised biotites and vermiculites. Mineral Mag 38, 121-137.

Friolo, K.H., RAY, A.S., StuART, B.H. \& Thomas, P.S. (2004). Degradation of historic sandstone buildings of Sydney. In Proceed ings of the 7 th Australasian Masonry Conference, Masia, M. (Ed.) pp. 420-427. Newcastle, Australia: University of Newcastle. mal analysis of heritage stones. J Therm Anal Col 80, 559-563. Eriolo, K.H., Ray, A.S., Stuart, B.H. \& Thomas, P.S. (2005b) Investigation of the degradation of sandstones in Sydneys heritage buildings. In Structural Analysis of Historical Constructions: Possibulities of Numerical and Experimental Techniques, Vol. 1, Modena, C., Lourenco, P.B. \& Roca, P. (Eds.), pp. 23 244. London: Taylor and Francis.

H. \& RAY, A. (2003). Characterisation of An heritage buildings. $J$ Cult Her 4, 211-220.
ALL, P.L. (1980). The application of electron spin resonance spectroscopy to studies of clay minerals: 1. Isomorphous substithions 321-335.

SSSAN, M.S. \& SALEM, S.M. (2002). Distribution and influence of iron phases on the physico-chemical properties of phyllosil.

kaolin deposits of the coastal plain of $\mathrm{Geos}$ values among the Carolina. Clay Clay Miner 2, 229-235.

IP, K.H., Stuart, B.H., Ray, A.S. \& Thomas, P.S. (2008a). A Sydney sandstone. Spectrochim Acta A 71, 1032-1035.

(2.H. ST OAKT, B.H., THOMAS, P.S. \& RAY, A.S. (2008b). Therm characterisation of the clay binder in heritage Sydney sandstones. J Therm Anal Cal 92, 97-100.

. in the investigation of kaolinite-group minerals. Clay Clay Miner 29, 23-30.

Matden, P.J. \& Meads, R.E. (1967). Substitution by iron in kaolinite. Nature 215, 844-846,

aynard, R.N., Milliman, N. \& IanNichli, J. (1969). A method for removing titanium dioxide impurities from kaolin. Cla Clay Miner 17, 59-62.

McBride, M.B., Pinnavaia, T.J. \& Mortland, M.M. (1975). Perturbation of structural $\mathrm{R}^{3}$

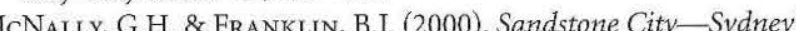
Dimension Stone and Other Sandstone Geomaterinls. Sydney: Geological Society of Australia

MeadS, R.E. \& Malden, P.J. (1975). Electron spin resonance in natural kaolinites containing $\mathrm{Fe}^{3+}$ and other transition meta ions. Clay Miner 10, 313-345.

MHRA, O.P. \& JACKSON, M.L. (1960). Iron oxides removal from soils and clays by dithionite-citrate system buffered with sodium bicarbonate. Clay Clay Miner 7, 317-327.

(1580). Iron

MuRRAY, H.H. (1995). Clays in industry and the environment. In Proceedings of the 10th International Clays Conference, ChurchMelbourne: CSIRO Publishing.

eetit, S. \& Decarreau, A. (1990). Hydrothermal $\left(200^{\circ} \mathrm{C}\right)$ synthe sis and crystal chemistry of iron-rich kaolinites. Clay Miner 25

181-196.
oscoe, R., BuUrman, P. \& Velthorst, E.J. (2000). Disruption of soil aggregates by varied amounts of ultrasonic energy in gen and $\delta^{13} \mathrm{C}$ distribution in particle-size fractions. Eur $I$ Sol Sci 51, 445-454

Rozenson, I. \& Heller-Kallat, L. (1977). Mössbauer spectra of dioctahedral smectites. Clay Clay Miner 25, 94-101.

RUTLEDGE, E.M., WiLDinG, L.P. \& ElFieLD, M. (1967). Automated particle-size separation by sedimentation. Proc Soil Sci Soc

Amer $31,287-288$.
ChmidT, M.W., Rumpel, C. \& Koget-KNabner, I. (1999). Evaluation of an ultrasonic dispersion procedure to isolate primary WEAvB C. (1968). Flectron microprobe study of keolin. Clay Clay Miner 16, 187-189. 